Article

\title{
Synthesis of Ni-Ti Coatings on Different Metallic Substrates by Mechanical Alloying and Subsequent Laser Treatment
}

\author{
Vladislav Yu Zadorozhnyy ${ }^{1, *}$, Aamir Shahzad ${ }^{1}$, Mikhail D. Pavlov ${ }^{1}$, Anatoly M. Chirkov ${ }^{2}$, \\ Dmitry S. Zagrebin ${ }^{2}$, Renata S. Khasenova ${ }^{3}$, Aleksandr I. Novikov ${ }^{1}$ and Sergey D. Kaloshkin ${ }^{1}$ \\ 1 National University of Science and Technology (MISIS), Moscow 119049, Russia; \\ aamirshah66@yahoo.com (A.S.); mkpavlovd@gmail.com (M.D.P.); nalil@yandex.ru (A.I.N.); \\ kaloshkin@misis.ru (S.D.K.) \\ 2 Laser Innovation Technology Center (VLITC), Kirov 610004, Russia; techlaser@mail.ru (A.M.C.); \\ zagrebin@laserintech.ru (D.S.Z.) \\ 3 Graduate School of Environmental Studies, Tohoku University, Sendai 980-8576, Japan; rick817@mail.ru \\ * Correspondence: vuz@misis.ru; Tel.: +7-495-638-4413
}

Received: 17 May 2018; Accepted: 22 June 2018; Published: 27 June 2018

\begin{abstract}
In this work, we proposed a novel mechanical alloying method to deposit $\mathrm{Ni}_{x}$-Ti $i_{x}$ intermetallic coating on various metallic substrates using laser treatment. Three different substrates (Al-based alloy, Ti-based alloy, and hypoeutectoid steel) were used, and 50-70 $\mu \mathrm{m}$ thick $\mathrm{Ni}_{x} \mathrm{Ti}_{x}$ coating was deposited during the process. For mechanical alloying, we used a self-constructed vibratory ball mill (single chamber) and for laser treatment, we used a "TrumpfTruDisk 1000" machine equipped with a four-dimensional control system "Servokon" designed specifically for experimental studies. Different laser beam intensities were used for laser operation. The cross-sectional microstructures of coatings were studied using a scanning electron microscope equipped with a Bruker energy-dispersive X-ray Spectrometer (EDS). Additional investigation of a cross-sectional area of one of the $\mathrm{Ni}_{x} \mathrm{Ti}_{x}$-coated samples was performed with field emission high-performance SEM and focused ion beam (FIB). Phase compositions of the obtained coatings, before and after laser treatment, were analyzed using X-Ray diffraction method. After the deposition process, the micro-hardness of the coatings was measured using a Vickers hardness tester. The structure and morphology of the obtained coatings were investigated.
\end{abstract}

Keywords: Ni-Ti intermetallics; laser treatment; mechanical alloying; coating

\section{Introduction}

Intermetallic $\mathrm{Ni}_{x} \mathrm{Ti}_{x}$ compounds are well known for their unique properties such as good ductility at room temperature, enhanced vibration-damping capacity, and corrosion resistance in seawater [1-3]. Researchers are interested in these compounds due to their potential use as a functional material in many engineering applications, i.e., active, adaptive structures, as well as medical and dental appliances [4-6]. Many technological approaches such as conventional powder metallurgy [7], self-propagating high-temperature synthesis [8], explosive shock-wave compression [9], and mechanical alloying (MA) [10] have been used to produce $\mathrm{Ni}_{x} \mathrm{Ti}_{x}$ intermetallic using elemental powders of $\mathrm{Ni}$ and $\mathrm{Ti}$. According to previous research, MA of 50Ni-50Ti elemental powder mixture can lead to a nanocrystalline solid solution and amorphous phase formation [11-13].

Several investigations are dedicated to the synthesis of NiTi intermetallic. Unlike other traditional coating techniques (thermal spray, CVD, PVD, etc.), mechanical alloying (MA) is a solid-state technique used to produce alloys and compounds that are either complicated or impossible to produce by melting 
or casting methods. The difference between the properties of coating material and substrate material does not affect the formation of good aluminide and other coatings using the MA method [14-16]. MA is a comparatively low-cost method that can produce coatings with controllable thickness and can get strong bonding between the coating material and the substrate avoiding adverse chemical reactions $[17,18]$.

Mechanical alloying forms intermetallic compounds inside a ball mill due to abrupt rise in temperature during deformation and impact; however, to get stable and homogenous intermetallic coating, annealing is necessary to produce the required phase [19]. Unfortunately, the difference in the melting points of the coating and the substrate materials often preclude effective annealing processing. In this study, instead of traditional furnace annealing, we used laser treatment of the MA coatings. By controlling the laser intensity, the formation of intermetallic phases can be initiated without interacting with the substrate material [20-24].

We have previously conducted other MA deposition investigations related to the deposition of hydroxyapatite [25] and various other intermetallic coatings (TiAl, NiAl etc.) [26-32]. The MA deposition of the $\mathrm{Ni}_{x} \mathrm{Ti}_{x}$ intermetallic compound on different metallic substrates reported here is an extension of our previous research.

The aim of our current research is to design basic principles of a relatively new method for the $\mathrm{Ni}_{x} \mathrm{Ti}_{x}$ intermetallic coatings deposition on different metallic substrates (Al-based alloy, Ti-based alloy, and hypoeutectoid steel) by using a combination of mechanical alloying in a vibratory ball mill and subsequent laser treatment. To this end, most suitable parameters for mechanical alloying and laser treatment will be determined in this work. The structure, morphology, and microhardness of the obtained coatings will be investigated.

\section{Materials and Methods}

$\mathrm{Ti}(99.96 \%)$ and $\mathrm{Ni}(99.98 \%)$ powders were used as raw materials for coatings. The elemental powders with stoichiometric composition of Ni-Ti were mechanically alloyed in a vibratory ball mill. The substrates were affixed to the top inside the milling vial. An Al-based alloy (Duralumin, analog of the 2017A alloy), a Ti-based alloy (analog of the Grade2 alloy), and a hypoeutectoid steel $(0.45 \mathrm{wt} \% \mathrm{C})$ were used as substrate materials. All the substrate samples were $30 \mathrm{~mm}$ in diameter and $1 \mathrm{~mm}$ in thickness. The hardness of the substrates was measured before the coating and was found to be approximately $115 \mathrm{HV}$ for the Al-based alloy substrate, $320 \mathrm{HV}$ for the Ti-based alloy substrate, and $230 \mathrm{HV}$ for the hypoeutectoid steel substrate.

An Akashi hardness-testing machine (MVK-HVL) (Mitutoyo, Kawasaki, Japan) was used to measure the microhardness of the samples. The microhardness testing was performed with a load of $200 \mathrm{~g}$ and a 10-second indentation dwell time. Each sample received eight to ten indentations. Minimum space of two to five diagonals of indentation prints was left between the neighboring indentations [33].

The amplitude of self-constructed vibratory ball mill (VM) was $13 \mathrm{~mm}$ with a frequency of $50 \mathrm{~Hz}$. The $4 \mathrm{~mm}$-diameter stainless steel ball-bearing balls were used as grinding media. According to T. Mandal et al. [34], the $4 \mathrm{~mm}$ balls and $13 \mathrm{~mm}$ amplitude are optimal conditions for mechanical alloying to achieve a synthesized nanostructured powder. E.V. Shelekov and T.A. Sviridova proved that the optimum ball-to-powder mass ratio is 10:1 [35], so we used this mass ratio in our current research. The total weight of the powder mixture was 3 grams for a $30 \mathrm{~cm}^{3}$ vial of VM. The milling process was performed with four 15-min milling runs with 15-min cessations between the runs to air-cool the milling vial and its contents. This procedure allowed us to achieve thetotal milling time of one hour. No process control agents were used during the milling process.

Phase compositions of the coatings were investigated by using DRON X-ray diffraction (XRD) diffractometer (Research and production enterprise "Bourevestnik", Saint Petersburg, Russian Federation) analysis using $\mathrm{CuK} \alpha$ radiation and vertical position of the sample ( $2 \theta$ angles from $30^{\circ}$ to $120^{\circ}$; Step: $0.1^{\circ}$; Time per step: $5 \mathrm{~s}$; Beam size: $6-8 \mathrm{~mm}$ ). The lattice parameters and the 
phase compositions were determined with an accuracy of $\pm 0.0001 \mathrm{~nm}$ and $\pm 5 \%$, respectively [36]. The crystallite size (coherent scattering domain) in the powders was determined from the broadening of diffraction line profiles that were fitted with the Cauchy functions. The obtained uncertainty in the crystallite sizes was $\pm 5 \mathrm{~nm}$ [37]. The percentage of the amorphous phase was determined using the kinematic standard method [35] and the annealed nickel powder as a standard.

The cross-sectional microstructures of the coatings were studied using a scanning electron microscope ZEISS ULTRA 55 Gemini at an accelerating voltage of $15 \mathrm{kV}$. The microscope was equipped with a Bruker energy-dispersive X-ray Spectrometer (EDS) (Bruker, Fremont, CA, USA).

Additional investigation of a cross-sectional area of one of the $\mathrm{Ni}_{x} \mathrm{Ti}_{x}$-coated samples was performed with field emission high-performance SEM (Carl Zeiss Group, Oberkochen, Germany) and micro milling Focused ion beam (FIB) Dualbeam JEOL JIB-4600F (JEOL Ltd., Tokyo, Japan) with an accelerating voltage of $10 \mathrm{kV}$. This method allows control of the ion-milling process while simultaneously providing SEM viewing and analysis of the abrasive-free cross section.

A Trumpf Tru Disk 1000 machine (Trumpf, Lübeck, Germany) equipped with a four-dimensional control system "Servokon" specifically designed for experimental studies was used for laser treatment of the obtained coatings. The machine was equipped with an argon gas blowing setup. Different laser beam intensities were used for laser treatment. These regimes provided different intensities of the laser beam. The beam diameter $(d)$ was $0.4 \mathrm{~mm}$. The main processing parameter was the total energy per unit area $(E)$. The equation used to calculate $E$ and an example of its use were shown in our previous work [27].

\section{Results and Discussion}

The phase and structural transformation of the obtained coatings are presented in Table 1. It is obvious that the chemical reaction between the $\mathrm{Ni}$ and Ti components of the powder mixture was not $100 \%$ complete during the MA process. Therefore, the peaks from the initial components $\mathrm{Ti}$ and/or $\mathrm{Ni}$ were detected on the XRD patterns of the coatings. Laser treatment resulted in phase transformation in the obtained coating and, in some cases, a comparatively more homogeneous structure was observed. The parameters of the MA process remained the same for all the substrates but laser treatment regimens were changed during the experiment.

After one hour of milling in the vibratory ball mill with almost all types of the substrate materials, comparatively broadened XRD peaks were observed. Such peaks correspond to the amorphous phase and the nanostructure of the obtained coatings (Table 1). When the same coating was exposed to laser treatment, the phase composition was observed to have a more relaxed crystallite structure as confirmed by changes in the XRD peaks and total crystallization of the amorphous phase.

Best results were found in the case of the Ti-based alloy substrate, where we found $25 \%$ by volume of the NiTi phase and $20 \%$ by volume of the $\mathrm{NiTi}_{2}$ phase, after laser treatment at $3.4 \mathrm{~J} / \mathrm{mm}^{2}$ (Figure 1 and Table 1).

It should be noted that $55 \%$ (by volume) of the observed Ti phase corresponds approximately to the uncoated substrate composition, which should be expected to be detected due to inexact focus of the $x$-ray beam. But, the resulted coating was quite homogeneous and covered almost all the substrate surface, before (Figure 2a) and after laser treatment (Figure 2d). Therefore, we believe that the chosen regime of laser treatment, in the case of the Ni-Ti coating deposition on the Ti-based alloy substrate, provides full-phase transformation in the coating layer due to a relatively small amount of the total energy per unit area $E\left(E=3.4 \mathrm{~J} / \mathrm{mm}^{2}\right)$.

The laminar structure of the coating obtained by MA (Figure 2a), can be clearly seen, which is typical for MA coatings $[15,29]$. Some layers correspond to the Ni phase (Figure 2b), some other correspond to the Ti phase (Figure 2c). But after the laser treatment, the phase composition of the obtained MA coating became more homogeneous (Figure 2d-f). 
Table 1. Phase composition and structural parameters of the Ni-Ti coatings.

\begin{tabular}{|c|c|c|c|}
\hline Phase Composition & Volume Fraction, $\%$ & Latticeparameter, $\mathrm{nm}$ & Crystallitesize, $\mathrm{nm}$ \\
\hline \multicolumn{4}{|c|}{ MA depositionof the NiTipowdermixture on Al-basedalloysubstrate } \\
\hline $\mathrm{Al}$ & 15 & A: 0.4079 & 25 \\
\hline $\mathrm{NiTi}$ & 2 & A: 0.2999 & 10 \\
\hline $\mathrm{Ti}_{2} \mathrm{Ni}$ & 13 & A: 1.0997 & 10 \\
\hline Amorphousphase & 70 & - & - \\
\hline \multicolumn{4}{|c|}{ The same sample after MA depositionandlasertreatment $E=8.2 \mathrm{~J} / \mathrm{mm}^{2}$} \\
\hline $\mathrm{Al}$ & 90 & A: 0.4041 & $>500$ \\
\hline $\mathrm{Al}_{2} \mathrm{Ti}$ & 10 & $\begin{array}{l}\text { A: } 0.3976 \\
\text { C: } 2.4361\end{array}$ & 30 \\
\hline \multicolumn{4}{|c|}{ The same sample after MA depositionandlasertreatment $E=6.8 \mathrm{~J} / \mathrm{mm}^{2}$} \\
\hline $\mathrm{Al}$ & 95 & A: 0.4033 & 100 \\
\hline $\mathrm{Ti}_{2} \mathrm{Al}_{5}$ & 5 & $\begin{array}{l}\text { A: } 0.6188 \\
\text { C: } 0.4644\end{array}$ & 10 \\
\hline \multicolumn{4}{|c|}{ MA depositionof the NiTipowdermixture on Ti-basedalloysubstrate } \\
\hline Ti-alpha & 5 & $\begin{array}{l}\text { A: } 0.2905 \\
\text { C: } 0.4650\end{array}$ & 10 \\
\hline $\mathrm{Ni}$ & $\begin{array}{l}5 \\
5 \\
5\end{array}$ & A: 0.3540 & 10 \\
\hline $\mathrm{NiTi}$ & $\begin{array}{l}5 \\
5 \\
5\end{array}$ & A: 0.3008 & 10 \\
\hline $\mathrm{Ti}_{2} \mathrm{Ni}$ & $\begin{array}{l}5 \\
5 \\
5\end{array}$ & A: 1.1377 & 10 \\
\hline Amorphousphase & 80 & - & - \\
\hline \multicolumn{4}{|c|}{ The same sample after MA depositionandlasertreatment $E=3.4 \mathrm{~J} / \mathrm{mm}^{2}$} \\
\hline Ti- alpha & 55 & $\begin{array}{l}\text { A: } 0.2943 \\
\text { C: } 0.4682\end{array}$ & $>500$ \\
\hline NiTi & 25 & A: 0.2994 & $>500$ \\
\hline $\mathrm{NiTi}_{2}$ & 20 & A: 1.1309 & $>500$ \\
\hline \multicolumn{4}{|c|}{ MA depositionof the NiTipowdermixture on hypoeutectoidsteelsubstrate } \\
\hline Fe-alpha & 2 & A: 0.2880 & 10 \\
\hline $\mathrm{NiTi}$ & 2 & A: 0.3036 & 10 \\
\hline $\mathrm{Ti}_{2} \mathrm{Ni}$ & 6 & A: 1.1257 & 10 \\
\hline Amorphousphase & 90 & - & - \\
\hline \multicolumn{4}{|c|}{ The same sample after MA depositionandlasertreatment $E=13.6 \mathrm{~J} / \mathrm{mm}^{2}$} \\
\hline Fe-alpha & 80 & A: 0.2904 & $>500$ \\
\hline $\mathrm{Fe}_{2} \mathrm{Ti}$ & 15 & $\begin{array}{l}\text { A: } 0.4838 \\
\text { C: } 0.7707 \\
\end{array}$ & 50 \\
\hline $\mathrm{NiTi}$ & 5 & A: 0.2916 & 50 \\
\hline
\end{tabular}

In the other two cases (Al-based alloy substrate and hypoeutectoid steel substrate), the total energy per unit area was too large. Therefore, laser treatment operation involved the phase formation incorporating the substrate materials ( $\mathrm{Al}$ and $\mathrm{Fe}$ ), see Table 1. For example, a layer enriched in $\mathrm{Al}$ is clearly seen on the coating side of the coating-substrate interface, after laser treatment at $E=8.2 \mathrm{~J} / \mathrm{mm}^{2}$ (Figure 3h). We already discussed this phenomenon in our previous work [27]. The same laminar microstructure of the coatings obtained by MA on the Al-based alloy substrate and hypoeutectoid steel substrate is clearly shown in Figure 3. 

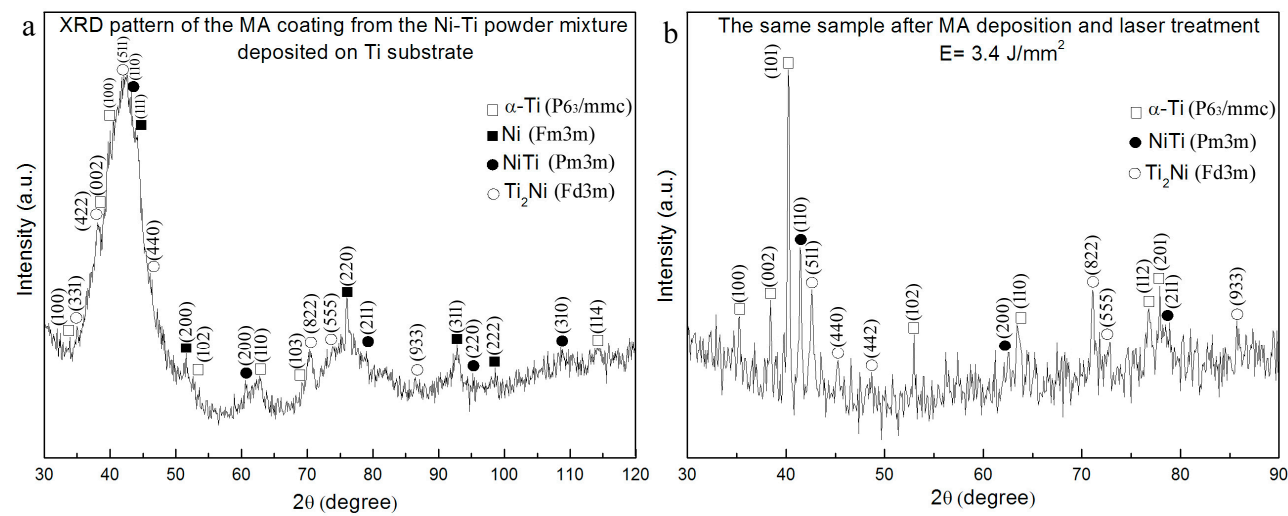

Figure 1. The XRD pattern of Ni-Ti coatings on Ti-based alloy substrate (a) after MA deposition, and $(\mathbf{b})$ after laser treatment with the total energy per unit area of about $3.4 \mathrm{~J} / \mathrm{mm}^{2}$.
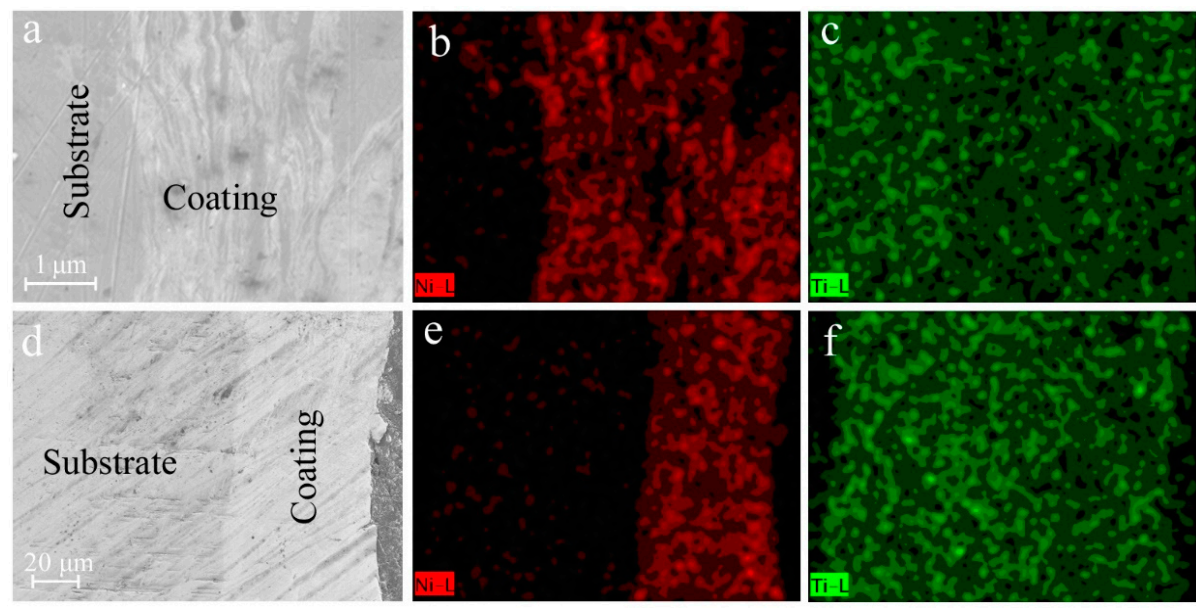

Figure 2. Cross-section SEM images and element mapping of the Ni-Ti coatings on the Ti-based alloy substrate after MA: (a) a general view of the microstructure; (b) contents of Ni; (c) Ti. Cross-section SEM images, and element mapping of the Ni-Ti coatings on the Ti substrates after MA and subsequent laser treatment with the total energy of $3.4 \mathrm{~J} / \mathrm{mm}^{2}$ : (d) a general view of the structure; (e) contents of $\mathrm{Ni}$; (f) Ti.
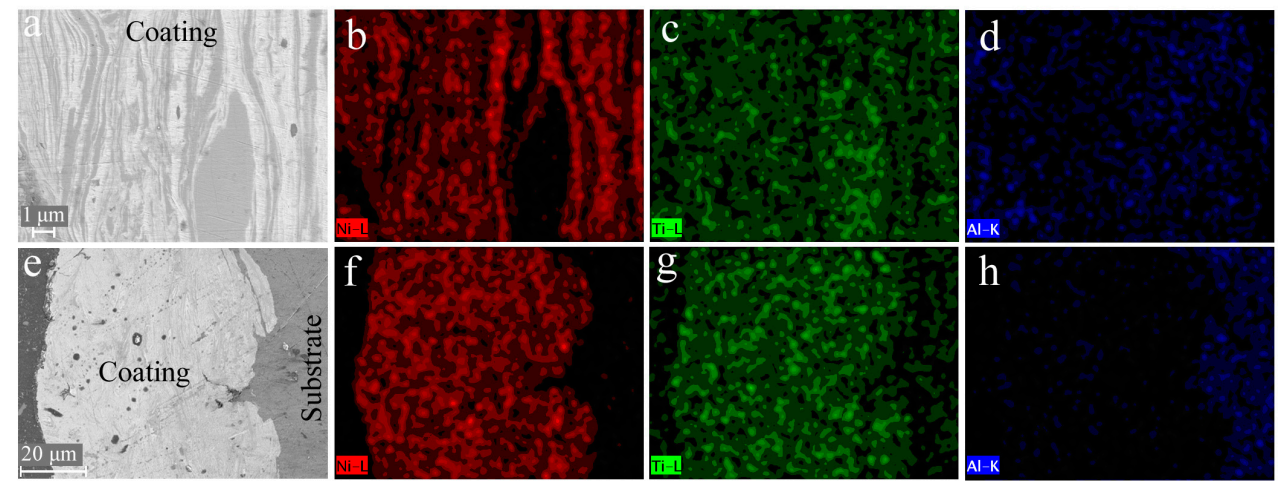

Figure 3. Cross-section SEM images and element mapping of the Ni-Ti coatings obtained by MA: a general view of the microstructure of the coating, (a) obtained on the Al-based alloy substrate; (b) contents of $\mathrm{Ni}$; (c) $\mathrm{Ti}$; (d) $\mathrm{Al}$ and a general view of the microstructure of the coating; (e) obtained on the hypoeutectoid steel substrate, contents of (f) Ni; (g) Ti; (h) Al. 
The resulting thickness of the obtained MA coatings (before and after laser treatment) was about 50-70 $\mu \mathrm{m}$ in the case of the Ti-based alloy substrate, as shown in Figure 4 . This was also valid for the coatings obtained on other types of the substrates (Al-based alloy and hypoeutectoid steel).

Microhardness measurements of the deposited $\mathrm{Ni}_{x} \mathrm{Ti}_{x}$ coatings and the substrates are presented in Table 2. The experimental results indicate that the surface hardness of the deposited $\mathrm{Ni}_{x} \mathrm{Ti}_{x}$ coatings had an increased hardness value as compared to the parent materials due to high density of crystalline defects presumably present in the coatings. After laser treatment, the grain structure became more homogeneous and stable due to redistribution of defects, recovery, formation and migration of small-angle grain boundaries (polygonization). These results are closer to the previous works provided by Mokgalaka et al. and Hiraga et al. [38,39].

The case of the coating on a hypoeutectoid steel substrate, laser annealed at $E=13.6 \mathrm{~J} / \mathrm{mm}^{2}$ was chosen as a useful example of the reactions produced by laser annealing because this case had the highest laser annealing energy. Examination of this specimen illustrates phase transformations seen in many of the coatings during laser annealing.
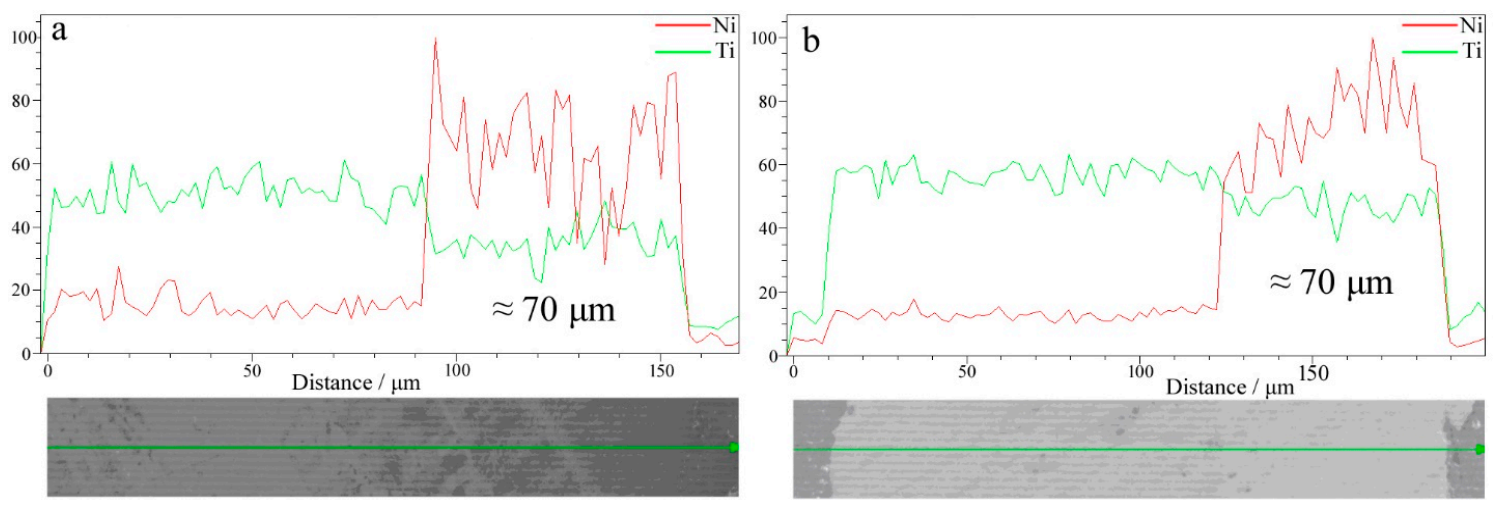

Figure 4. The resulting thickness of the obtained Ni-Ti coatings on the Ti-based alloy substrate, (a) after MA deposition and (b) after laser treatment with the total energy per unit area of about $3.4 \mathrm{~J} / \mathrm{mm}^{2}$.

Table 2. Microhardness of the initial substrates and coatings, obtained by the MA and a subsequent laser treatment.

\begin{tabular}{cccc}
\hline \multicolumn{4}{c}{ Microhardness, HV } \\
\hline Substrate & Substrate before MA & MA Coating & After Laser Treatment \\
\hline \multirow{2}{*}{ Al-based alloy } & 115 & 410 & $450\left(E=8.2 \mathrm{~J} / \mathrm{mm}^{2}\right)$ \\
& & & $265\left(E=6.8 \mathrm{~J} / \mathrm{mm}^{2}\right)$ \\
\hline Ti-based alloy & 320 & 405 & $680\left(E=3.4 \mathrm{~J} / \mathrm{mm}^{2}\right)$ \\
Hypoeutectoid steel & 230 & 1115 & $775\left(E=13.6 \mathrm{~J} / \mathrm{mm}^{2}\right)$ \\
\hline
\end{tabular}

Figure 5 demonstrates cross-sectional area $(20 \mu \mathrm{m}$ width, $10 \mu \mathrm{m}$ height $)$ of the $\mathrm{Ni}_{x} \mathrm{Ti}_{x}$ coating on the hypoeutectoid steel observed with SEM and FIB methods. It can be clearly observed that the coating was formed in two ways: a well-mixed layer of an intermetallic steel-based matrix and a thin, less than $1 \mu \mathrm{m}$, non-uniform and particularly overlaying coat of pure Ti (Figure 5a). The pure $\mathrm{Ti}$ layer on the top has a relatively homogenous interface surface with a steel-based matrix. The steel-based matrix contains $8 \mathrm{wt} \%$ of Ti and $8 \mathrm{wt} \% \mathrm{Ni}$ uniformly distributed among the whole cross-sectional area with embedded $\mathrm{Fe}_{2} \mathrm{Ti}$ (see Table in Figure 5b, components detected by XRD) round-shape particles. Some matrix grains can be clearly seen on the cross-sectional view (dashed encircled areas in Figure 5c,d).

Also, a few particles of $\mathrm{Fe}_{2} \mathrm{Ti}$ were incorporated in the matrix grains and most of them were distributed among the matrix grain boundaries (red outlined in grain body and yellow outlined in 
the boundaries of the matrix), Figure $5 c, d$. The average particle size was $300 \mathrm{~nm}$. The elemental powder particles $(\mathrm{Ni}, \mathrm{Ti})$ were forcibly embedded into the hypoeutectoid steel substrate and then recrystallized with matrix grains into $\mathrm{Fe}_{2} \mathrm{Ti}$. Some of the particles were formed in the grain boundaries, which can be explained by the effects on diffusion of the impurities to the dislocation groups formed due to severe plastic deformation during treatment, recovery, and grain (matrix and intermetallic) growth. Thus, after laser treatment, intermetallic compound reacted with Fe in the matrix and formed $\mathrm{Fe}_{2} \mathrm{Ti}$; elemental $\mathrm{Ni}$ and $\mathrm{Ti}$ were uniformly distributed among the substrate. However, in future this phenomenon can be studied more deeply.

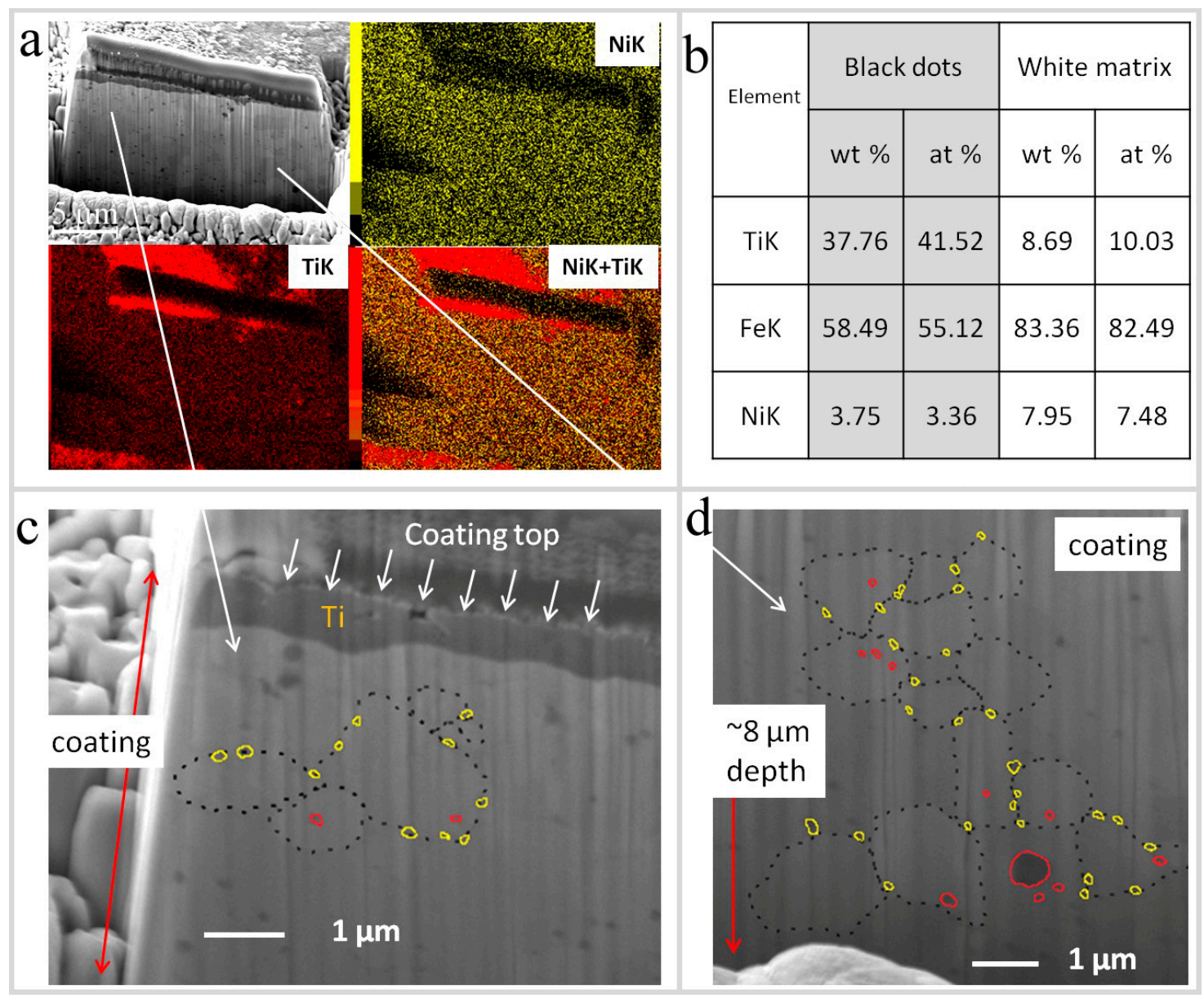

Figure 5. (a) A cross-sectional view of Ni-Ti coating on the hypoeutectoid steel substrate after 1-h treatment and the laser treatment $E=13.6 \mathrm{~J} / \mathrm{mm}^{2} ;(\mathbf{b})$ element analysis data, a table of the element content in the cross-sectional area; (c,d) magnified SEM image of visible grain boundaries of the steel matrix and embedded/recrystallized intermetallic incorporations.

\section{Conclusions}

In the present work, possibility of the $\mathrm{Ni}_{x} \mathrm{Ti}_{x}$ coatings deposition on different metallic substrates by using MA with subsequent laser treatment was investigated. Three different substrates (Al-based alloy, Ti-based alloy, and hypoeutectoid steel) were used, and 50-70 $\mu \mathrm{m}$ thick $\mathrm{Ni}_{x} \mathrm{Ti}_{x}$ coating was deposited during the process. Best results were found in the case of the Ti-based alloy substrate, where we observed a large amount of the Ni-Ti intermetallic compounds after laser treatment at $3.4 \mathrm{~J} / \mathrm{mm}^{2}$, but it was not a single-phase NiTi intermetallic compound. After the MA process, broadened XRD peaks and a wide halo was observed. Such a wide XRD halo and broadened peaks correspond to the amorphous phase and the nanostructure of the obtained coatings. When the same coating was exposed to laser treatment, the phase composition was observed to have a more relaxed crystallite 
structure. The obtained $\mathrm{Ni}_{x} \mathrm{Ti}_{x}$ coatings have relatively high microhardness in comparison with the substrate material. For example, microhardness of the coating deposited on the Ti based alloy (320 HV) was increased up to $680 \mathrm{HV}$. This relatively high level of microhardness should be explained by a non-equilibrium condition of the material and high density of crystalline defects in the coatings obtained by MA deposition.

According to the results of our previous and current work, we concluded that laser treatment of the MA coatings with a relatively higher energy per unit area is involved in the reaction of a deeper layer (of the substrate materials) in the phase transformation process. Therefore, laser treatment operation is involved in the formation of the phases corresponding to substrate materials. Laser treatment of the MA coatings with a relatively low energy per unit area does not cause final phase transformation in the coating layers. Therefore, to find an optimal regime of laser treatment is very important for obtainingsingle-phase and homogeneous coating structures.

Author Contributions: V.Y.Z. analyzed the data, writed-reviewed and edited of the manuscript; A.S. preparated original draft of the manuscript and validated it; M.D.P., D.S.Z., R.S.K. and A.I.N. performed the experiments; A.M.C. contributed materials and analysis tools; S.D.K. conceived and designed the experiments.

Funding: This research was funded by the Ministry of Education and Science of the Russian Federation within the framework of the Increase Competitiveness Program of MISiS, from the grant of the Russian Ministry of Education and Science grant number 11.1934.2017/ПЧ and by Russian Science Foundation grant number 17-73-20272.

Conflicts of Interest: The authors declare no conflict of interest.

\section{References}

1. Igharo, M.; Wood, J.V. Compaction and Sintering Phenomena in Titanium-Nickel Shape Memory Alloys. Powder Metall. 1985, 28, 131-139. [CrossRef]

2. Filip, P.; Musialek, J.; Lorethová, H.; Nieslanik, J.; Mazanec, K. TiNi shape memory clamps with optimized structure parameters. J. Mater. Sci. Mater. Med. 1996, 7, 657-663. [CrossRef]

3. Li, B.Y.; Rong, L.J.; Li, Y.Y.; Gjunter, V.E. Electric resistance phenomena in porous Ni-Ti shape-memory alloys produced by SHS. Scr. Mater. 2001, 44, 823-827. [CrossRef]

4. Prokofyev, E.; Gunderov, D.; Prokoshkin, S.; Valiev, R. Microstructure, mechanical and functional properties of NiTi alloys processed by ECAP technique. In Proceedings of the ESOMAT 2009 8th European Symposium on Martensitic Transformations, Prague, Czech Republic, 7-11 September 2009; p. 6028.

5. Kapanen, A.; Ilvesaro, J.; Danilov, A.; Ryhänen, J.; Lehenkari, P.; Tuukkanen, J. Behaviour of Nitinol in osteoblast-like ROS-17 cell cultures. Biomaterials 2002, 23, 645-650. [CrossRef]

6. Hernández, R.; Polizu, S.; Turenne, S.; Yahia, L. Characteristics of porous nickel-titanium alloys for medical applications. Biomed. Mater. Eng. 2002, 12, 37-45. [PubMed]

7. Grummon, D.S. Thin-Film Shape-Memory Materials for High-Temperature Applications. JOM 2003, 49, 24-32. [CrossRef]

8. Jarfors, A.E.W.; Sim, G.C.; San, T.E. Influence of Process Parameters on Reaction Products during Self-Propagating High-Temperature Synthesis of Porous NiTi. Mater. Sci. Forum 2003, 475, 437-438. [CrossRef]

9. Han, X.; Zou, W.; Wang, R.; Zhang, Z.; Li, T.; Yang, D. Microstructure of TiNi Shape-Memory Alloy Synthesized by Explosive Shock-Wave Compression of Ti-Ni Powder Mixture. J. Mater. Sci. 1997, 32, 4723-4729. [CrossRef]

10. Takasaki, A. Mechanical Alloying of the Ti-Ni System. Phys. Status Solidi 1998, 169, 183-191. [CrossRef]

11. Liang, G.X.; Wang, E.D.; Li, Z.M. Effects of ball milling intensity on structural changes in mixed 50Ni-50Ti powders during mechanical alloying process. Mater. Sci. Technol. 1995, 11, 347-350. [CrossRef]

12. Ye, L.L.; Liu, Z.G.; Raviprasad, K.; Quan, M.X.; Umemoto, M.; Hu, Z.Q. Consolidation of MA amorphous NiTi powders by spark plasma sintering. Mater. Sci. Eng. A 1998, 241, 290-293. [CrossRef]

13. Gu, Y.W.; Goh, C.W.; Goi, L.S.; Lim, C.S.; Jarfors, A.E.W.; Tay, B.Y.; Yong, M.S. Solid state synthesis of nanocrystalline and/or amorphous 50Ni-50Ti alloy. Mater. Sci. Eng. A 2005, 392, 222-228. [CrossRef] 
14. Mohammadnezhad, M.; Shamanian, M.; Enayati, M.H.; Salehi, M.; Hoseynian, A. Microstructures and properties of NiAl-TiC nanocomposite coatings on carbon steel surfaces produced by mechanical alloying technique. Surf. Coat. Technol. 2014, 238, 180-187. [CrossRef]

15. Romankov, S.; Kaloshkin, S.D.; Hayasaka, Y.; Sagdoldina, Z.H.; Komarov, S.V.; Hayashi, N.; Kasai, E. Structural evolution of the Ti-Al coatings produced by mechanical alloying technique. J. Alloys Compd. 2009, 483, 386-388. [CrossRef]

16. Romankov, S.; Kaloshkin, S.D.; Hayasaka, Y.; Hayashi, N.; Kasai, E.; Komarov, S.V. Effect of process parameters on the formation of Ti-Al coatings fabricated by mechanical milling. J. Alloys Compd. 2009, 484, 665-673. [CrossRef]

17. Yazdani, A.; Zakeri, A. An insight into formation of nanostructured coatings on metallic substrates by planetary ball milling. Powder Technol. 2015, 278, 196-203. [CrossRef]

18. Varol, T.; Canakci, A. Synthesis and characterization of nanocrystalline Al 2024-B4C composite powders by mechanical alloying. Philos. Mag. Lett. 2013, 93, 339-345. [CrossRef]

19. Thein, M.A.; Lu, L.; Lai, M.O. Effect of milling and reinforcement on mechanical properties of nanostructured magnesium composite. J. Mater. Process. Technol. 2009, 209, 4439-4443. [CrossRef]

20. Podrabinnik, P.; Grigoriev, S.; Shishkovsky, I. Laser post annealing of cold-sprayed Al/alumina-Ni composite coatings. Surf. Coat. Technol. 2015, 271, 265-268. [CrossRef]

21. Shen, L.D.; Huang, Y.H.; Tian, Z.J.; Hua, G.R. Direct Fabrication of Bulk Nanostructured Ceramic from Nano- $\mathrm{Al}_{2} \mathrm{O}_{3}$ Powders by Selective Laser Sintering. Key Eng. Mater. 2007, 329, 613-618. [CrossRef]

22. Ajdelsztajn, L.; Jodoin, B.; Schoenung, J.M. Synthesis and mechanical properties of nanocrystalline Ni coatings produced by cold gas dynamic spraying. Surf. Coat. Technol. 2006, 201, 1166-1172. [CrossRef]

23. Ajdelsztajn, L.; Schoenung, J.M.; Jodoin, B.; Kim, G.E. Cold spray deposition of nanocrystalline aluminum alloys. Metall. Mater. Trans. A 2005, 36, 657-666. [CrossRef]

24. Bray, M.; Cockburn, A.; O'Neill, W. The Laser-assisted Cold Spray process and deposit characterisation. Surf. Coat. Technol. 2009, 203, 2851-2857. [CrossRef]

25. Zadorozhnyy, V.Y.; Kaevitser, E.V.; Kopylov, A.N.; Borisova, V.V.; Sudarchikov, R.S.; Khasenov, R.S.; Gorshenko, M.V.; Zadorozhnyy, M.Y.; Kaloshkin, S.D. Synthesis of the hydroxyapatite coatings on the Ti substrates by mechanical alloying. Surf. Coat. Technol. 2015, 281, 157-163. [CrossRef]

26. Shahzad, A.; Zadorozhnyy, V.Y.; Pavlov, M.D.; Zheleznyi, M.V.; Chirkov, A.M.; Zagrebin, D.S.; Semenov, D.V.; Khasenov, R.S.; Kaloshkin, S.D. Deposition of the Ti-Al coatings on different metallic substrates by mechanical alloying and subsequent laser treatment. J. Alloys Compd. 2018, 731, 1295-1302. [CrossRef]

27. Zadorozhnyy, V.Y.; Shahzad, A.; Pavlov, M.D.; Kozak, D.S.; Chirkov, A.M.; Zagrebin, D.S.; Khasenov, R.S.; Komarov, S.V.; Kaloshkin, S.D. Synthesis of the Ni-Al coatings on different metallic substrates by mechanical alloying and subsequent laser treatment. J. Alloys Compd. 2017, 707, 351-357. [CrossRef]

28. Zadorozhnyy, V.; Kaloshkin, S.; Tcherdyntsev, V.; Gorshenkov, M.; Komissarov, A.; Zadorozhnyy, M. Formation of intermetallic Ni-Al coatings by mechanical alloying on the different hardness substrates. J. Alloys Compd. 2014, 586, S373-S376. [CrossRef]

29. Zadorozhnyy, V.Y.; Kaloshkin, S.D.; Churyukanova, M.N.; Borisova, Y.V. Formation of Intermetallic Ni-Al Coatings by Mechanical Alloying with Different Intensities. Metall. Mater. Trans. A 2013, 44, 1179-1784. [CrossRef]

30. Zadorozhnyy, V.; Kaloshkin, S.; Kaevitser, E.; Romankov, S. Coating of metals with intermetallics by mechanical alloying. J. Alloys Compd. 2011, 509, S507-S509. [CrossRef]

31. Khasenova, R.S.; Komarov, S.V.; Zadorozhnyy, V.Y. Mechanical plating of Al/CNT composite coatings on aluminum substrates. J. Alloys Compd. 2017, 707, 238-244. [CrossRef]

32. Shahzad, A.; Zadorozhnyy, V.Y.; Pavlov, M.D.; Semenov, D.V.; Kaloshkin, S.D. Study and development of $\mathrm{NiAl}$ intermetallic coating on hypo-eutectoid steel using highly activated composite granules of the Ni-Al system. Int. J. Mater. Res. 2018, 109, 63-67. [CrossRef]

33. Panchenko, E.V.; Skakov, Y.A. Laboratoriya Metallografii [Laboratory of the Metallographic]; Metallurgy Publications: Moscow, Russia, 1965; p. 440. (In Russian)

34. Mandal, T.; Mishra, B.K.; Garg, A.; Chair, D. Optimization of milling parameters for the mechanosynthesis of nanocrystalline hydroxyapatite. Powder Technol. 2014, 253, 650-656. [CrossRef] 
35. Shelekhov, E.V.; Sviridova, T.A. Simulation of Balls Motion and Heating in Planetary-Type Mill. The Effect of Processing Modes onto Mechanical Activa-tion Products of Ni and Nb Powders Mixture. Materialoved 1999, 13-22.

36. Shelekhov, E.V.; Sviridova, T.A. Programs for X-ray analysis of polycrystals. Met. Sci. Heat Treat. 2000, 42, 309-313. [CrossRef]

37. Yagodkin, Y.D.; Dobatkin, S.V. Application of electron microscopy and x-ray structural analysis for the determination of sizes of structural elements in nanocrystalline materials (Review). Inorg. Mater. 2008, 44, 1520. [CrossRef]

38. Mokgalaka, M.N.; Pityana, S.L.; Popoola, P.A.I.; Mathebula, T. NiTi intermetallic surface coatings by laser metal deposition for improving wear properties of Ti-6Al-4V substrates. Adv. Mater. Sci. Eng. 2014. [CrossRef]

39. Hiraga, H.; Inoue, T.; Kamado, S.; Kojima, Y.; Matsunawa, A.; Shimura, H. Fabrication of NiTi intermetallic compound coating made by laser plasma hybrid spraying of mechanically alloyed powders. Surf. Coat. Technol. 2001, 139, 93-100. [CrossRef]

(C) 2018 by the authors. Licensee MDPI, Basel, Switzerland. This article is an open access article distributed under the terms and conditions of the Creative Commons Attribution (CC BY) license (http://creativecommons.org/licenses/by/4.0/). 